\title{
Microbial extremophiles in evolutionary aspect
}

\author{
Elena V. Pikuta and Richard B. Hoover \\ Astrobiology Laboratory, \\ NASA/MSFC/NSSTC, \\ 320 Sparkman Dr., Huntsville, AL 35805 USA
}

\begin{abstract}
The microflora of the cryosphere of planet Earth provides the best analogs for life forms that might be found in the permafrost or polar ice caps of Mars, near the surface of the cometary nuclei, or in the liquid water beneath the ice crusts of icy moons of Jupiter and Saturn. For astrobiology the focus on the study alkaliphilic microorganisms was enhanced by the findings of abundant carbonates and carbonate globules rimmed with possibly biogenic magnetites in association with the putative microfossils in the ALH84001 meteorite. Although the ALH84001 "nanofossils" were to small and simple to be unambiguously recognized as biogenic, they stimulated Astrobiology research and studies of microbial extremophiles and biomarkers in ancient rocks and meteorites. Recent studies of CI and CM carbonaceous meteorites have resulted in the detection of the well-preserved mineralized remains of coccoidal and filamentous microorganisms in cyanobacterial mats. Energy Dispersive X-ray Analysis has shown anomalous biogenic element ratios clearly indicating they are not recent biological contaminants.

This paper reviews microbial extremophiles in context of their significance to Astrobiology and the evolution of life. Extremophilic microorganisms on Earth are models for life that might endure high radiation environments in the ice near the surface of comets or on the icy moons of Jupiter and Saturn and in the seafloor deep beneath the icy crusts of Europa and Enceladus.
\end{abstract}

KEY WORDS: extremophilic microorganisms, ecosystems, evolution, astrobiology, meteorites

\section{INTRODUCTION}

During evolution the sequence and direction of mutations in ancestor cells allowed them to exhibit various adaptations in response to the environmental changes. This process was complicated and included not only multi-factor influences, but probably, back and forth vectors as well. During this process, biological cells could have experienced several extreme physico-chemical factors at the same time. As a result, newly formed organisms appeared to have resistance, tolerance, or even developed an obligate requirement (phily) to the single or multiple extreme environmental factors. Furthermore, at the present time we have observed the existence of acidophilic thermophiles, halo-alkaliphilic thermophiles, barophilic hyperthermophiles, halo- or alkaliphilic psychrophiles, etc. The genetics of extremophilic microorganisms could be considered as the enciphered code of environmental effects in the past and probably have enough flexibility to provide a necessary "buffer pool" towards future stressful changes. Without this flexibility life would soon become extinct during any kind of the global cataclysm on climatic or geophysical levels. Except for the geophysical influence of the environment affecting living cells, another very important factor was developed, and it was designated as biological. Life itself, even at the level of monotypic or pure culture always has competitive relations among cells: those that eat more and breathe better are the strongest and predominant, and the weaker forms die out. On the interspecies level this is expressed even more effectively: the specific behavior and physiological specifics such as an excretion of antibiotics, poisons, or an inhibition by trivial end metabolic products, all of these to some extent limit the neighborhood of the surrounding species, that led to the creation of the functionally and physiologically adjusted microbial consortia, and then communities. Symbiotic relations between different kinds of microbial organisms are reflected on the cytological and genetic levels of eukaryotic organisms (mitochondria and chloroplasts) for energetic efficiency, and also in such a phenomenon as the binary microbial cultures (cases when microbiologists cannot separate cells of two symbiotically related (by undetected trace compounds or by vitamin exchange) microbial cultures. It is quite possible that such relationships initially have also been developed in extreme environments.

The interaction of growing and accumulating organisms within the environment and other biological species consequently led to the creation of balanced ecosystems. All geo-paleontological deposits represent an encoded chronology of biological activity. The formation of minerals and fossils is the direct or indirect result of biological 
activity. Fossilized carbon, oil, elemental sulfur, methane, gold, iron pyrites, etc., were all formed in certain periods of evolution under specific circumstances, where local or wide-spread regions had experienced the demographic explosion of certain extremophilic populations, and the formation of rocks and minerals in such regions occurred due to the bioleaching processes or just to pure metabolic activity of microbial agents. Following the global climatic changes and the geo-formation processes some populations with unique physiologies were completely replaced by others forever, and this can be observed on mineral and rock deposits. For this reason all modern extremophiles could appropriately be called relics, because they do have a genome that memorized environmental history, and this feature makes the study of extremophiles important to many fundamental sciences. Indeed, the modern face of the Earth is a product of the interaction of biological agents (mostly microorganisms) and minerals. The soil formation was the clue to the distribution of plants on Earth, and it still remains an unsolved problem in biology. During this process, the extremophilic microorganisms probably played a pioneering role. It is now well established that eukaryotic organisms cannot exist without prokaryotes; it is equally true for both plants (rhizosphere of root system, protective surface flora) and animals (flora of intestine and skin surfaces). The participation of extremophilic bacteria in such ecosystems is not excluded (bacteria develop at extreme acidity in the stomach which results in chronic disease, the microbial process of methanogenesis in intestine, etc.).

\section{CLASSIFICATION OF MICROBIAL COMMUNITIES}

During Earth's evolution, accompanied by geophysical and climatic changes, a number of ecosystems have been formed. These ecosystems differ by the broad variety of physicochemical and biological factors that compos our environment. Traditionally, $\mathrm{pH}$ and salinity are considered as geochemical extremes, as opposed to the temperature, pressure and radiation that are referred to as physical extremes ${ }^{1}$. Life inhabits all possible places on Earth interacting with the environment and within itself (cross species relations). In nature it is very rare when an ecotope is inhabited by a single species. As a rule, most ecosystems contain the functionally related and evolutionarily adjusted communities (consortia and populations). In contrast to the multicellular structure of eukaryotes (tissues, organs, systems of organs, whole organism), the highest organized form of prokaryotic life in nature is the benthic colonization in biofilms and microbial mats. In these complex structures all microbial cells of different species are distributed in space and time according to their functions and to physicochemical gradients that allow more effective system support, self-protection, and energy distribution. In vitro, of course, the most primitive organized structure for bacterial and archaeal cultures is the colony, the size, shape, color, consistency, and other characteristics of which could carry various specific characteristics on species or subspecies levels. In table 1 all known types of microbial communities are shown ${ }^{2}$. In deep underground (lithospheric) and deep-sea ecosystems additional factors - pressure, and irradiation - could also be added to this classification.

Currently the best-studied ecosystems are: the human body (due to the medical importance), and fresh water and marine ecosystems (due to the environmental concerns).

For a long time, extremophiles were terra incognita, since the environments with aggressive parameters (compared to the human body temperature, $\mathrm{pH}$, salinity, and pressure) were considered a priori as dead zones. It took time to find out that the environments with extreme physico-chemical and climatic parameters are inhabited by a wide spectrum of different microorganisms. In chronological sequence the discoveries of extremophiles are as follows:

Slight acidophilic property ( $\mathrm{pH} 4-6$ ) in many fungi has long been known, but the first obligately acidophilic bacterium described was Acidithiobacillus ferrooxidans (formally Thiobacillus ferrooxidans), later thermophilic lithotrophic acidophiles were found, and the hyper-acidophilic species of the genus Picrophilus growing at negative $\mathrm{pH}$ values $^{3}$ were described in 1996.

The epoch of study of thermophilic microorganisms starts with the discovery of Thermus aquaticus ${ }^{4}$, and now the maximum temperature for growth at $113{ }^{\circ} \mathrm{C}$ was found for Pyrolobus fumarii. ${ }^{5}$ Another hyperthermophilic microorganism, strain 121(not validly published) that was isolated by Kashefi and Lovley ${ }^{6}$ survives for short periods of time at $130^{\circ} \mathrm{C} .^{7}$

The first mention of the term "psychrophile" was made by Schmidt-Nielsen in 1902 for the description of bacteria capable of growth at $0{ }^{\circ} \mathrm{C}^{8}$, but Arctic diatoms had already been studied more then one hundred years ago without applying this term. ${ }^{9}$ With the development of a special technique of cooled instruments and well equipped cold rooms it has become possible to study truly psychrophilic microorganisms. In our Astrobiology Laboratory at NASA/MSFC/NSSTC the bacterial growth (in pure culture) was determined at $-5^{\circ} \mathrm{C}$ on a liquid media, ${ }^{10,11,12}$ and our Russian colleagues successfully cultivated aerobic bacterial cultures on solid agar media also at $-5{ }^{\circ} \mathrm{C}$. ${ }^{13}$ The observations of living microorganisms in situ at $-20^{\circ} \mathrm{C}$ in highly mineralized media were reported previously. ${ }^{14}$ 
Table 1. Known types of microbial communities.

\begin{tabular}{|c|c|c|c|}
\hline Types of communities: & pH & $\mathrm{NaCl}, \%(\mathrm{w} / \mathrm{v})$ & Temperature, ${ }^{\circ} \mathrm{C}$ \\
\hline $\begin{array}{l}\text { 1. Freshwater psychrophilic } \\
\text { 2. Freshwater, meso-thermal } \\
\text { 3. Freshwater moderately thermophilic } \\
\text { 4. Freshwater thermophilic }\end{array}$ & $5-7$ & $0-1$ & $\begin{array}{c}<10 \\
15-40 \\
50-60 \\
70-110\end{array}$ \\
\hline $\begin{array}{l}\text { 5. Marine psychrophilic } \\
\text { 6. Marine, meso-thermal } \\
\text { 7. Marine moderately thermophilic } \\
\text { 8. Marine thermophilic }\end{array}$ & 8 & $3-4$ & $\begin{array}{c}<10 \\
15-40 \\
50-60 \\
70-120\end{array}$ \\
\hline $\begin{array}{l}\text { 9. Alkaliphilic psychrophilic } \\
\text { 10. Alkaliphilic mesophilic } \\
\text { 11. Alkaliphilic moderately thermophilic } \\
\text { 12. Alkaliphilic thermophilic }\end{array}$ & $9-11$ & $0-1$ & $\begin{array}{c}<10 \\
15-40 \\
50-60 \\
70-110\end{array}$ \\
\hline $\begin{array}{l}\text { 13. Haloalkaliphilic psychrophilic } \\
\text { 14. Haloalkaliphilic mesophilic } \\
\text { 15. Haloalkaliphilic moderately thermophi }\end{array}$ & $9-10$ & $3-25$ & $\begin{array}{l}<10 \\
15-40 \\
50-60\end{array}$ \\
\hline $\begin{array}{l}\text { 16. Halophilic psychrophilic } \\
\text { 17. Halophilic mesophilic } \\
\text { 18. Halophilic moderately thermophilic }\end{array}$ & 8.0 & 3-30 & $\begin{array}{l}<10 \\
15-40 \\
50-60\end{array}$ \\
\hline $\begin{array}{l}\text { 19. Acidophilic mesophilic }{ }^{* 1} \\
\text { 20. Acidophilic moderately thermophilic } \\
\text { 21. Acidophilic thermophilic }\end{array}$ & $0-4$ & $0-2$ & $\begin{array}{c}15-40 \\
50-60 \\
70-120\end{array}$ \\
\hline
\end{tabular}

The first mentioned alkaliphile was the bacterium Streptococcus faecalis, ${ }^{15}$ but several years earlier an article about alkalitolerant nitrifying bacteria was published. ${ }^{16}$ Extreme alkaliphiles belonging to genera Clostridium and Bacillus were isolated from soils, ${ }^{17}$ but truly alkaliphilic microorganisms belonging to separate genera such as Natronobacterium and Natronococcus were described later (Tindall et al., 1984). ${ }^{18}$

The study of halophilic microorganisms began with work on saline soils and lakes, and now the record of good growth for Haloferax mediterranei has been demonstrated at $30 \% \mathrm{NaCl}$.

The study of barophiles became possible after the development of deep-ocean submersible crafts. In the Black Smokers studies it was shown that there are microorganisms that require high pressure in addition to high temperature, and the highest known limit of life was detected at $100 \mathrm{MPa} .{ }^{19}$

The first radioresistant bacterium Deinococcus radiodirans was found during the process of food conservation and storage. This bacterium could survive ionizing irradiation and other DNA-damaging assaults at doses that are lethal to all other organisms. ${ }^{20}$ Among archaea the hyperthermophilic sulfur-reducing Thermococcus gammatolerans that is capable of resisting $30 \mathrm{kGy}$ of $\gamma$-irradiation was described comparatively recently. ${ }^{21}$

Anaerobiosis, as an alternative to the aerobic life, was discovered by Pasteur in his fermentation work, ${ }^{22}$ but an anaerobic technique for the cultivation of obligately anaerobic microorganisms was developed much later. ${ }^{23}$ Among the bacteria and archaea there are many anaerobic species, and most of them are not extremophiles. For this reason an anaerobiosis is not considered as imperative to extremophilic life. However, it should be remembered that the first life forms on early Earth were anaerobic extremophiles, and therefore, this capacity is a very important issue for the logical discussion about the limits of life.

\footnotetext{
* One exception - Thiobacillus halophilus - it has optimal $\mathrm{NaCl}$ concentration at 5-6\%(w/v) and maximum concentration at $24 \%(\mathrm{w} / \mathrm{v})$.
} 
From the systematics point of view, both eukaryotic and prokaryotic organisms represent life in extreme ecosystems, and the comparison of all taxa in complex biocoenosis of each ecosystem will provide answers to the fundamental questions of the origin, distribution, and evolution of life (direction of changes in the phenotype).

\section{MICROBIAL SPECIES WITHIN PHYSICO-CHEMICAL MATRIX}

If we consider the distribution of life in a matrix of $\mathrm{pH} /$ temperature, salinity/temperature, salinity/pH, radiation/temperature by placing the names of described known species of microorganisms on the corresponding matrix, the picture will be as follows. The diagram pH/Temperature (Fig. 1a) shows a gray painted square in an area of neutral $\mathrm{pH}$ and mesophiles/moderate-thermophiles limits; this square represents the region of a majority of known microbial species that includes saprophytes, pathogens, and environmentally important agents responsible for the balance of trophic chains in surrounding ecosystems. On the left side of this square the distribution of acidophilic species is shown. As we can see, none of the acidophilic psychrophilic species were described and found; this supports the point of view about the primary origin of acidophiles on hot cooling Earth. The area of hyperthermophilic and moderately thermophilic species of acidophiles is quite busy and is mostly "populated" by a species of archaea. The most thermostable species is Pyrolobus fumarii that could survive $30-60 \mathrm{~min}$ in autoclave at $120{ }^{\circ} \mathrm{C}$, and the neutrophilic but not validly published strain 121 that grows at a temperature higher than $120^{\circ} \mathrm{C}$ and survives for a short period of time at $130{ }^{\circ} \mathrm{C}$. The most alkalitolerant described species of archaea among the hyperthermophiles is Thermococcus alkaliphilus, which is able to grow at $\mathrm{pH} 10.5$. On the right side of the gray painted square the distribution of mesophilic and moderately thermophilic species of microorganisms is shown; it includes bacteria, cyanobacteria, and archae-bacteria. As it was discussed previously, ${ }^{24}$ mesophilic cyanobacteria are the leaders in alkalitolerancy among all living organisms. The recently described psychrotolerant species Trichococcus patagoniensis is able to grow at $\mathrm{pH} 10.0$ and its other specific feature is the ability to grow at $-5^{\circ} \mathrm{C}$. Before the discovery of this species the record of growth at subzero temperatures was established for psychrophilic species of sulfate-reducing bacteria. ${ }^{25}$

The diagram of salinity/pH (Fig.1b) shows the distribution of known species of microorganisms within this matrix. On the diagram on the left side the gray painted square represents the area of a majority of known species of microorganisms (saprophytes, pathogens, and environmental agents). As we can see, the extreme acidophiles appear in regions of salinity before $5 \%$. Species of the genera Natronobacterium and Natronorubrum are able to grow at $30 \%$ (w/v) salinity. Cyanobacteria are spread to the $\mathrm{pH} 12$ area and limited by $15 \%$ salinity. This diagram, once again, confirms the hypothesis about the later appearance of halophily during the evolution of life. The accumulation and solubility of $\mathrm{Na}^{+}$and $\mathrm{Cl}^{-}$ions in water became possible only in the latest stages of Earth's evolution.

The diagram of salinity/Temperature (Fig. 1c) shows the presence of a mesophilic and moderately thermophilic species of microorganisms in extreme saline area (25-30\%); none of the hyperthermophilic species are known at extreme salinity. Probably, again, the rule of Earth's life evolution is working: the first organisms were non-halophilic hyperthermophiles; the primordial ocean was not salty at all.

The final diagram (Fig.1d) shows the distribution of known species in matrix of radiation/temperature. Three species (one of them an archaebacterium) could tolerate $30 \mathrm{kGy}$ irradiation level. Does that suggest that the level of irradiation on Early Earth was around this number? Or is it possible that these microorganisms originated elsewhere in the cosmos and then were transported by comets and meteorites to Earth? To resolve these questions there is a need for Science to acquire more data (this area of extremophily has not been thoroughly studied).

Looking at these diagrams the logical question arises: What direction of biological changes (adaptation, mutations, transformation into metabolically inactive forms, etc.) did the ancestor cells experience during the Earth evolution? Is it appropriate to suggest that an exclusively single source of homogenous cell culture started biological evolution on Earth, or were there several physiologically different types of cell cultures that interacted and developed into present day life? So, who was the first ancestor from the whole diverse extremophilic microbial world that we observe today? If the formation of any planet required a certain high-temperature regime then it is obvious, the hyperthermophilic microorganisms have priority as the role of ancestors. Psychrophily must have developed after a significant temperature drop on the planet surface. Free oxygen at the formation and cooling of the planet is excluded, and this means that anaerobic types of metabolisms would have been primary. Acidophily probably was the initial in biological history on Earth, and only after certain mineral precipitation and enough buffer concentration of $\mathrm{CO}_{2}$ in the air did the alkaliphily occur. Halophily perhaps developed as the latest when the arid climate dominated the land parts of Earth. Due to the tiny sizes of bacterial and archaean cells, the pressure does not have a significant influence on them as it has for the highly organized forms of life with macroscopic sizes, but still the barophily was formed among microorganisms of deep-sea and deep-underground ecosystems. 
$-5^{\circ} \mathrm{C} \quad \mathrm{SRB}^{*}$ Wrichococcuspatagoniensis

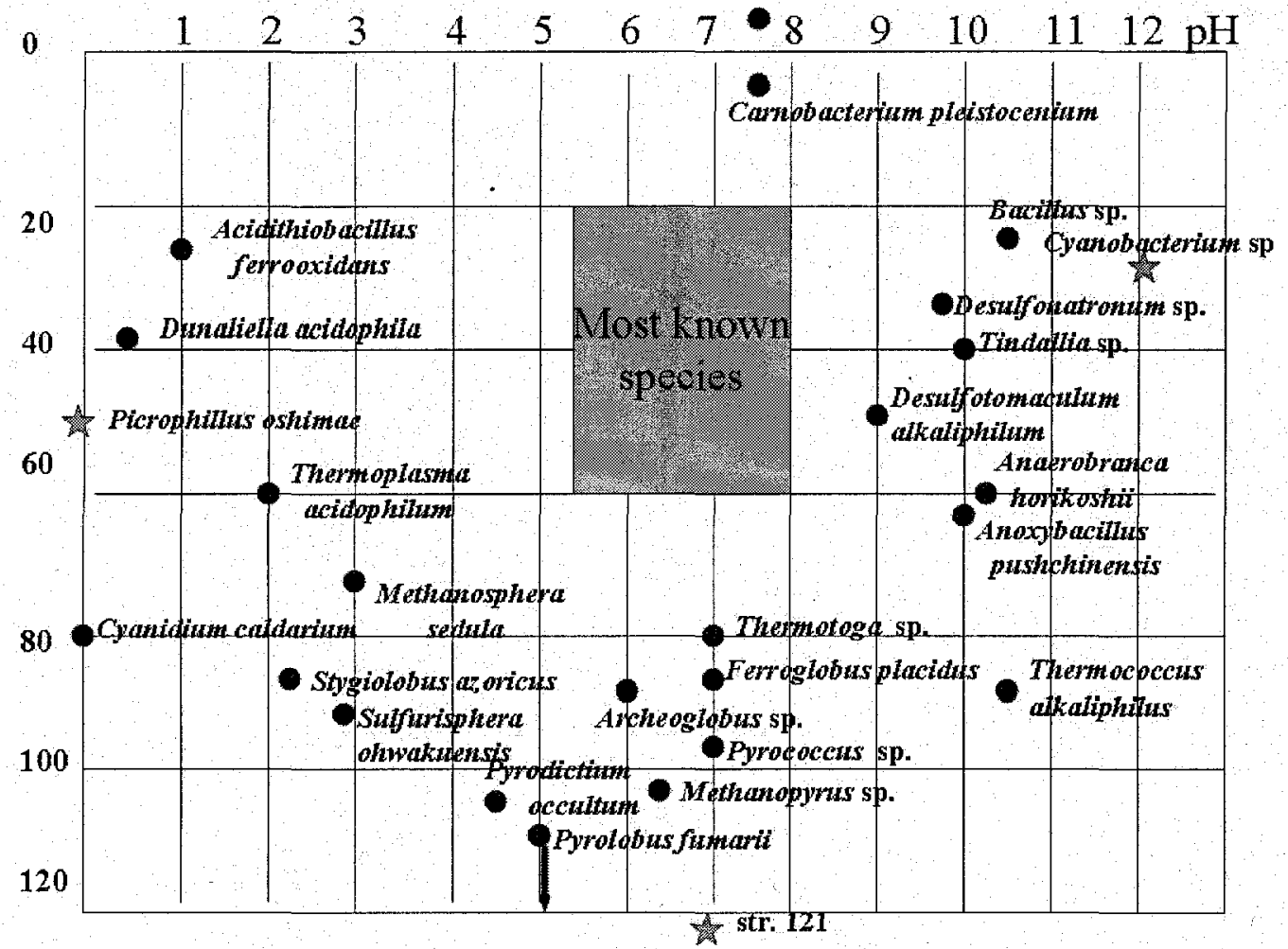

Fig.la

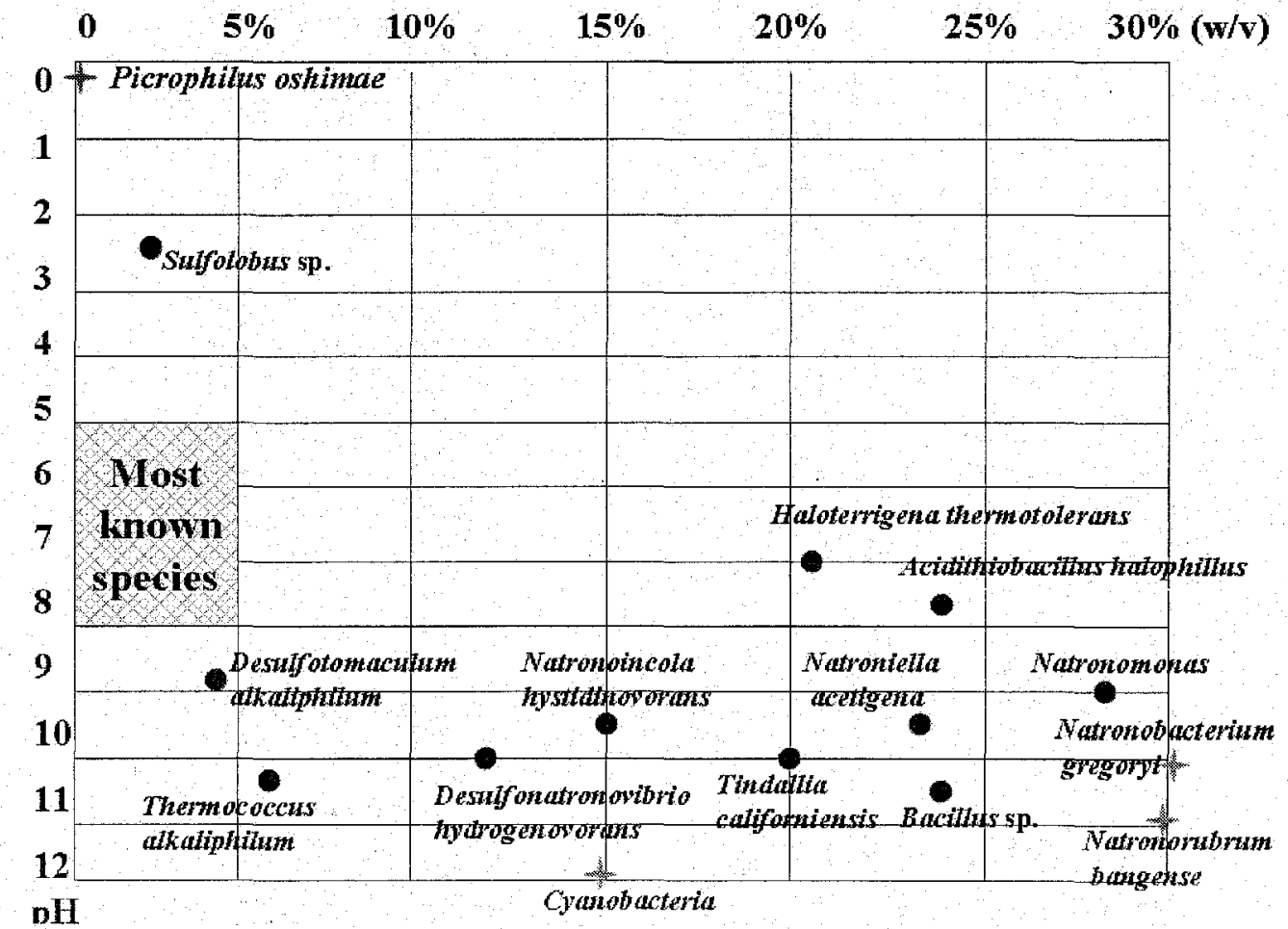

Fig. 1b 


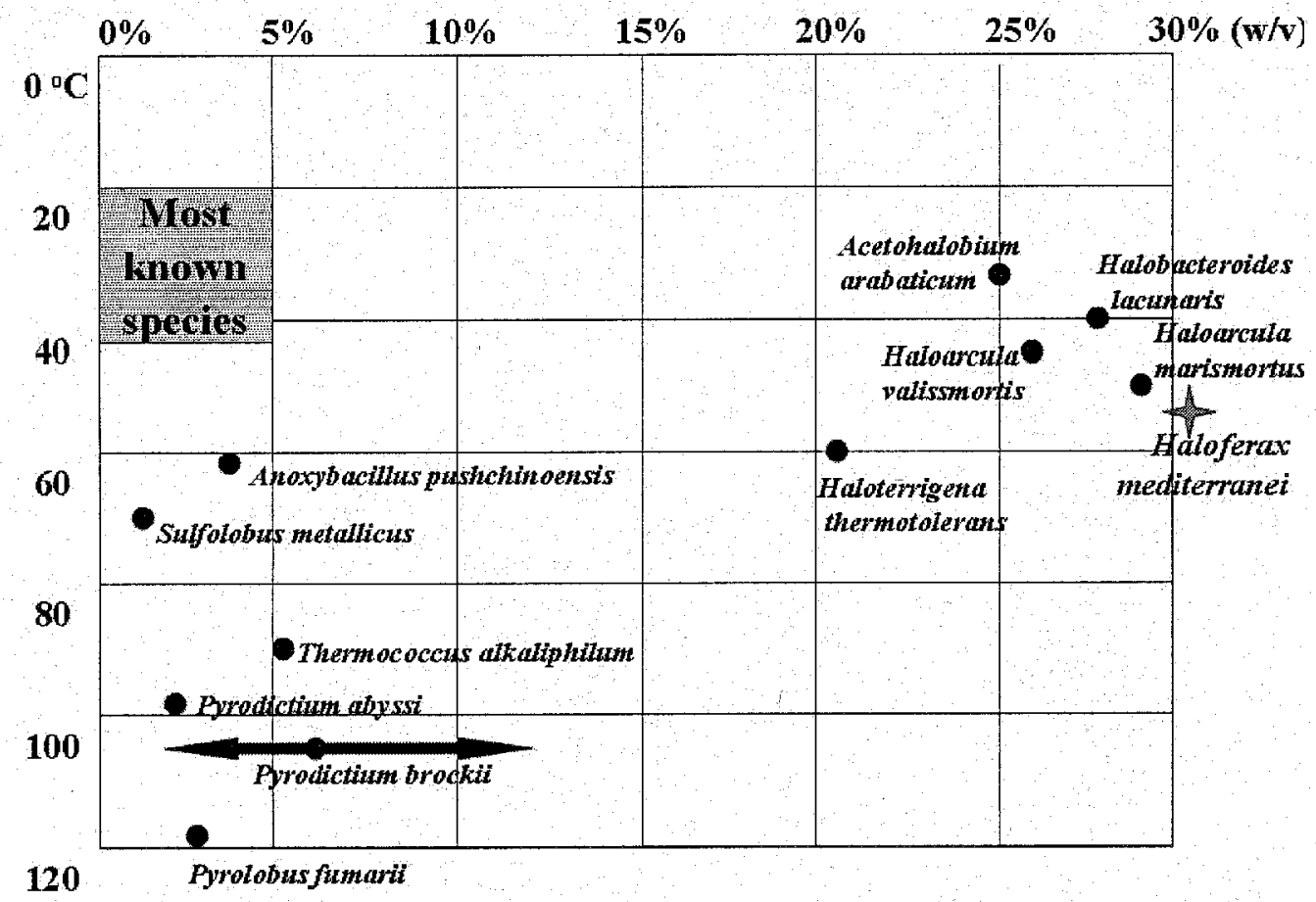

Fig. 1c

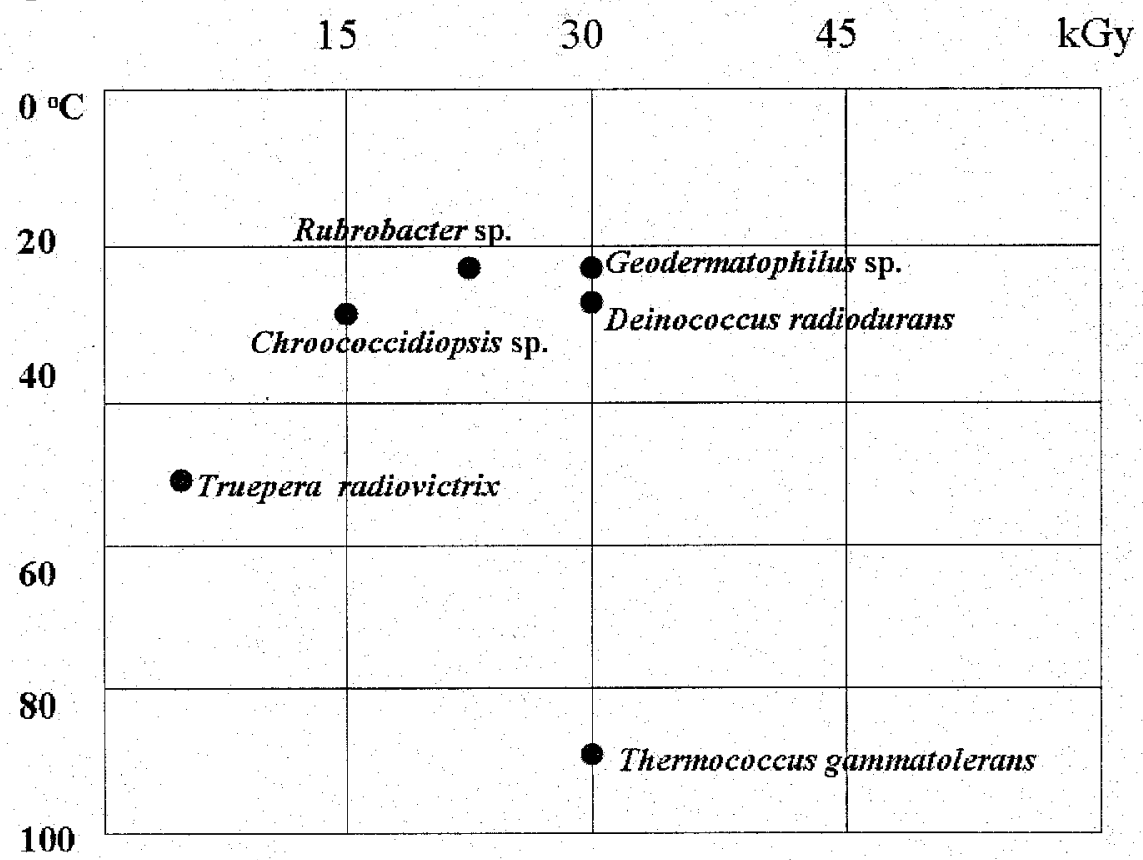

Fig. 1d

Fig. 1. Distribution of known species of microorganisms in the matrix: (a) pH/Temperature, ${ }^{\circ} \mathrm{C} ;{ }^{*}$ SRB- 5 genera of psychrophilic sulfate-reducing bacteria (Knoblauch et al., 1999); (b) Salinity, \% (w/v)/pH; (c) Salinity, \% (w/v)/Temperature, ${ }^{\circ} \mathrm{C}$; (d) Radiation, kGy/Temperature, ${ }^{\circ} \mathrm{C}$. 
Another fundamental question in biology arises: How is life distributed after the delivery transportation or after self-origin on the planet? Was it from the surface to center, or opposite, from the center (initial requirement of high pressure and absence of light) to the surface? What is the situation with the cultivation of extremophilic microorganisms today? The molecular biologists have pronounced that microbiologists have successfully cultivated in vitro only one percent (or less) of all microbial diversity that exists in nature. Based on the data of genomic libraries constructed by the 16 S rRNA gene sequence analysis, approximately $99 \%$ of the whole gene pool of prokaryotes still remains unknown. At the present time around 7300 species of bacteria and archaea are validly published. Since Dr. Petri introduced the method of cultivation on an agar solid media, using dishes, which are now named for him, one hundred years have passed, but hyperthermophilic anaerobes were discovered only in the past twenty five years or so. Of course, the percent of cultivated extremophilic microorganisms compared to other "normal" bacteria and archaea is significantly lower. The development of biotechnology has tremendously stimulated the investigation of extremophiles. Today many laboratories in different countries are extensively involved in the study of these fascinating and critically important microorganisms.

\section{ASTROBIOLOGICAL SIGNIFICANCE OF EXTREMOPHILIC MICROORGANISMS}

The microflora of the cryosphere on our planet represents a good analog for the life forms that might be found in the permafrost or polar ice caps of Mars, near the surface of the nuclei of comets, or in the liquid water and the ice crusts of icy moons of Jupiter and Saturn. $10,26,27$ It is now well established that water ice exists today in a vast deposit at the North Polar Ice Cap of Mars. $28,29,30,31,32$ The Mars Global Surveyor had produced images of double-rimmed polygons on Mars that are consistent with the double-rimmed polygons in permafrost of Earth that are produced by expansion and contraction effects associated with the seasonal water-ice freeze-thaw cycles. ${ }^{33}$ The High Energy Neutron detector aboard the Mars Odyssey spacecraft ${ }^{34}$ has also found that there are large water-rich permafrost areas, with contents up to $50 \%$ water by mass fraction, at both the North and South polar regions of Mars. In the northern latitudes, these water-ice layers of permafrost are very near the surface, but in the south they are covered by a thicker $(10-20 \mathrm{~cm})$ layer of soil. The water content of the Mars regolith was found to exceed $11 \%$ at latitudes greater than 60 degrees in both hemispheres. Two regions near the equator (Arabia Terra and Medusae Fossae) even exhibited 9-10\% water $^{35}$ with the lower layer of soil in the moistest region $(30 \mathrm{E}, 10 \mathrm{~N})$ having soil with over $16 \%$ of water by mass which is comparable to the water content (13-19\%) of tropical rain forest soil on Earth. ${ }^{36}$

The possibility that microbial extremophiles might thrive today (or be present in a cryopreserved state) in the water ice and permafrost in the modern Martian regolith is of great significance to Astrobiology. While it is generally accepted that the one common bond for all life known on Earth is the universal requirement for water, it is clearly not necessary that the water be found in liquid state in large bodies, such as seas or lakes. Many microorganisms grow within thin films of water in permafrost and in frozen rocks of the polar regions (cryptoendoliths). Microorganisms also inhabit acidic (acidophiles) and brine channels (halophiles) in glaciers..$^{10,37,38,39}$ On Earth, solar heating of low albedo rocks entrained in glaciers results in microenvironments (cryoconite ecosystems) with trapped liquid water, gasses, organic chemicals, and minerals that provide ideal conditions for the growth of both prokaryotic and eukaryotic microorganisms. The study of the species of Earth's microflora that thrive in the coldest regions of our planet is of great importance to the design and development of robotic systems that will be needed to search for biomarkers and evidence of past or present life on Mars, Europa, and other prime targets for Astrobiology research. The study of metabolically active microorganisms at low and/or subzero temperatures is of major interest to astrobiology, since most bodies of our Solar System are frozen worlds.

It has been shown that microorganisms can remain viable for geological periods of time when cryopreserved in

ice. ${ }^{40,41}$ It is well known that microbes are generally capable of remaining viable for very long periods of time when freeze-dried (lyophilization) and that some organisms can maintain metabolic activity at temperatures as low as $-20{ }^{\circ} \mathrm{C}$. Representatives of the genus Trichococcus have been found to be capable of replication and growth at $-5^{\circ} \mathrm{C}$ at both aerobic and anaerobic conditions. ${ }^{42}$

The importance of studying acidophilic microorganisms is primarily concerned with acidic thermal systems such as may exist on bodies of our solar system that have volcanic or tectonic activities. Evidence for ancient volcanic activity on Mars and Venus, and recent volcanic activity on Io has been revealed by the Viking, Pathfinder, Global Surveyor, Mars Odyssey, Voyager, Venera, and Magellan space missions with optical, ultraviolet, infrared, and radar images and IR, gamma-ray, and neutron spectral data (Pikuta and Hoover, 2004b). ${ }^{37}$ Much volcanic activity has also occurred on Venus, which is known as the most acidic planet of the Solar System. Venus is thought of as a twin planet of Earth although it rotates in the opposite direction. However it is much closer to the Sun and it has a surface 
temperature of around $470^{\circ} \mathrm{C}$, and an atmospheric pressure is equivalent to 100 times that of Earth's atmosphere. After the discovery of active microorganisms ${ }^{43}$ in Earth's atmosphere at an altitude of $44 \mathrm{~km}$ (level of stratosphere) the discussions about possible existence of life forms on acidic droplets in the cooler dense clouds of the Venus atmosphere has been triggered.

The Jovian moon Io presents the most active volcanic body of our Solar System with conditions that may be acceptable for the development of sulfur-dependent microorganisms. Io's volcanic activity could also provide acidic geysers and springs suitable for the development of acidophilic sulfur-metabolizing lithotrophs. There is also much evidence that beneath the fractured ice crust of Europa, a liquid water ocean exists. The Jovian tidal effects and/or hydrothermal vents could provide the heat necessary for the liquid water ocean underneath the crust of this icy moon. It is conceivable that acidophilic microorganisms might also inhabit acidic hydrothermal vents on Europa, ${ }^{44}$ and that psychrophiles could thrive in niches at interfaces between the liquid water and the ice sheet.

The importance of studying the alkaliphilic microorganisms for astrobiology was enhanced by the findings of abundant carbonates and carbonate globules rimmed with possibly biogenic magnetites in association with the putative microfossils in the ALH84001 meteorite. ${ }^{45,46}$ The study of this meteorite provided definitive evidence of the existence of carbonate minerals on Mars. The participation of microbial agents in the formation of carbonate systems on Earth was discussed previously. ${ }^{47}$ Even though the ALH84001 nano-structures were not of sufficient size as to be positively accepted as valid recognized microfossils, these results profoundly stimulated the study of meteorites, bacterial paleontology, and microbial extremophiles. The extensive research efforts triggered by the ALH84001 results have helped to define valid biomarkers and to delineate where and how to best search for evidence of life in Earth's most hostile environments and elsewhere in the Solar System.

Recent studies have resulted in the detection of evidence for the mineralized remains of a large and complex assemblage of diverse coccoidal and filamentous microorganisms and bacterial mats in the Orgueil (CI1) and Murchison (CM2) carbonaceous meteorites. ${ }^{48,49}$ These forms are much larger and more complex than the ALH84001 nanostructures and they exhibit features that provide clear associations with known morphotypes of all five orders of the Cyanobacteriaceae. The forms occur as spherical and irregular coccoids, sometimes in colonies with electron transparent carbonaceous mucilaginous envelopes. These morphotypes have characteristics of the Chroococcales and in pseudo-filaments with baeocyte-like forms consistent with the Pleurocapsales. These morphological simple forms are not so distinctive as the larger forms that occur as uniseriate and multiseriate unbranched and branched filaments and mats that have been found embedded in the meteorite rock matrix. The vast majorities of the filamentous forms found in freshly fractured surfaces of the meteorites are consistent in both size and detailed morphological features with the non-polarized filaments, carbon-rich sheaths, and mineralized trichomes of the Oscillatorialean cyanobacteria. However, the Orgueil meteorite has also been found to contain a number of other forms that have tapered polarized filaments and exhibit cross-wall constrictions, true and false branching and highly differentiated cells. Many of the tapered filaments appear to represent benthic forms attached to the substratum by basal heterocysts (occasionally exhibiting ellipsoidal akinetes) with detailed features characteristic of morphotypes of the genus Calothrix. The most distinctive of the Orgueil filaments are exceptionally well-preserved forms that are interpreted as representing morphotypes of the Orders: Nostocales and Stigonomatales. These microfossils have extremely complex and distinctive biogenic characteristics that cannot be confused with minerals and other abiotic microstructures. Energy Dispersive X-ray Analysis has revealed that they have anomalous $\mathrm{C} / \mathrm{O}, \mathrm{C} / \mathrm{N}$, and $\mathrm{C} / \mathrm{S}$ ratios that clearly establish that they cannot be attribute to recent biological contaminants and the forms have been interpreted as indigenous microfossils. The detection of microfossils in carbonaceous meteorites supports the hypothesis proposed by Hoyle and Wickramasinghe in 1981 that comets and meteorites could be carriers and distributors of living cells in the Solar System. ${ }^{50,51}$

\section{EXTREMOPHILIC MICROORGANISMS INVESTIGATED FOR ASTROBIOLOGY RESEARCH}

It is well known that microbial extremophiles are of great importance in the rapidly emerging field of Astrobiology in order to help us understand where and how to search for evidence of life elsewhere in the Cosmos. Research carried out in the NASA/NSSTC has used a variety of samples collected during field expeditions to a number of the most extreme environments on Earth. These included:

1) Samples from cold regions of our planet - frozen Pleistocene thermokarst ponds, ice wedges, and permafrost of Fox Tunnel and Glaciers of Alaska; permafrost of the Kolyma lowlands of Northeastern Siberia; guano of the Magellanic penguins of southern Patagonia, Chile; and snow, rocks and deep ice cores from the Patriot Hills, Thiel Mountains, and Vostok Station, Antarctica;

2) Samples from acidic ecosystems- Chena Hot Springs near Fairbanks, Alaska; 
3) Samples from halo-alkaline ecosystems- soda lakes in California;

4) Samples from deep-sea hydrothermal vents- Rainbow Deep Sea Vent, Azores, Middle Atlantic);

5) Samples from geysers and moderate thermal springs- Alaska and California.

The following groups of microorganisms were isolated and studied. Five strains of alklaliphilic mesophilic bacteria were isolated in pure cultures and described from halo-alkaline systems of Owens Lake and Mono Lake in California. Four of them have been validly published and deposited in International Microbial Culture Collections:

1) Spirochaeta americana $\mathrm{ASpG}^{\mathrm{T}}$ was found to be the first obligate anaerobic and alkaliphilic free-living sugarlytic spirochete on the American continent; the peculiar feature of this unique strain is production of molecular hydrogen as a major end metabolic product that offers potential for biotechnology applications as an alternative fuel for the strategy of the Hydrogen economy;

2) Desulfonatronum thiodismutans $\mathrm{FMLl}^{\mathrm{T}}$ was also found to be the first obligately alkaliphilic sulfate-reducing bacterial species on the American continent, and as a specific feature of this strain differentiating it from Asian strains is that it has a chemolithotrophic metabolism that allows this bacterium to grow exclusively on hydrogen and $\mathrm{CO}_{2}$ without any organic substrates;

3) Tindallia californiensis $\mathrm{APO}^{\mathrm{T}}$ was described as an agent responsible for decomposition of proteolysis products and some organic acids; $;^{52}$ This species performs the function of a secondary anaerobe in anaerobic alkaliphilic microbial community of Mono Lake; This strain is capable of respiration by performing a Stickland reaction on certain pairs of amino acids;

4) Anaerovirgula multivorans $\mathrm{SCA}^{\mathrm{T}}$ was found as the cellulolytic agent in the anaerobic microbial community of Owens Lake, but subsequent study showed this process as very weak. The major trophic function for this species is degradation of proteolysis products molecules and some organic acids. This strain was found to be phylogenetically distant from known clostridial species and had taken a separate lineage on the separate genus level and separate species; ${ }^{53}$

5) Spirochaeta sp. ASpC2 ${ }^{\mathrm{T}}$ is now in preparation for publication; this obligately anaerobic and alkaliphilic strain was isolated from a cellulolytic enrichment culture from Owens Lake, and it has a number of physiological features differentiating it from other known free-living spirochetes.

From the acidic system of Chena Hot Spring in Alaska the obligately acidophilic strain $A G C 2^{\mathrm{T}}$ was isolated in pure culture. ${ }^{44}$ This mesophilic, spore-forming strain is able to grow on the medium with high concentrations of $\mathrm{Fe}^{2+}$ with $\mathrm{pH}$ 1.5-2.0. The taxonomic description of this strain is currently in preparation.

From a deep-sea hydrothermal vent the obligately sulfur-reducing archaebacterial strain OGL-20P ${ }^{\mathrm{T}}$ was isolated and described. This isolate belongs to a separate new species of the genus Thermococcus with proposed name $T$. thioreducens. $^{54}$

The study of samples from cold regions led to discovery of psychrotolerant Carnobacterium pleistocenium FTR $1^{\mathrm{T}}$ that was alive after remaining frozen for 32,000 years in the Pleistocene ice of a Thermokarst pond of the CRREL Fox Permafrost Tunnel near Fairbanks, Alaska. This facultatively anaerobic fermenting bacterium was described as a separate new species since it was different from known species both on genetic and phenotypic levels. ${ }^{41}$ This bacterium is of great importance to both Astrobiology and Paleontology. It is first a validly published species of the Pleistocene period and it was cryopreserved in ancient permafrost. It is also important to cryobiology by demonstrating that it is possible to extract living microorganisms from the ice and permafrost samples of other bodies of the Solar System.

Another interesting psychrotolerant sugarlytic bacterium Trichococcus patagoniensis PmagG $1^{\mathrm{T}}$ was isolated from penguin guano, and it was able to grow at $-5^{\circ} \mathrm{C}$ at aerobic and anaerobic conditions. This record is the lowest known temperature for growth of a pure culture. ${ }^{42}$ The description of the proteolytic psychrotolerant bacterium strain $P P P 2^{T}$ that represents a separate new genus and species is currently in preparation (source of isolation is also guano from the Magellanic penguin).

\section{CONCLUSIONS}

1) The formation of planets requires a high-temperature regime and therefore, the hyperthermophilic microorganisms have priority as the role of ancestors.

2) Psychrophily would have to have developed after a significant temperature drop on the planet surface.

3) Free oxygen at the formation and cooling of the planet is excluded, and that is why anaerobic types of metabolisms would have been primary.

4) Acidophily probably was the initial in biological history on Earth; Alkaliphily became possible after certain mineral precipitation and enough buffer concentration of $\mathrm{CO}_{2}$ in the air.

5) Halophily possibly developed as the latest when the arid climate dominated on the land parts of Earth. 


\section{REFERENCES}

1. B. Van Den Burg. "Extremophiles as a source for novel enzymes", Curr. Opin. Microbiol. 6, 213-218, 2003.

2. E. V. Pikuta, T. Itoh and R. B. Hoover. "Anaerobic decomposition of cellulose by alkaliphilic microbial community of Owens Lake, California", in: /Instruments, methods, and missions for astrobiology IX (R. B. Hoover, A. Yu. Rozanov, G. V. Levin, and G. R. Gladstone, eds.) Proc.SPIE 5906, 29-40, San Diego, USA, 2005 b.

3. C. Schleper, G. Pühler, H.P. Klenk and W. Zillig. "Picrophilus oshimae and Picrophilus torridus fam. nov., gen. nov., sp. nov., two species of hyperacidophilic, thermophilic, heterotrophic, aerobic archaea", Int. J. Syst. Bacteriol. 46, 814-816, 1996.

4. T. D. Brock and H. Freeze. "Thermus aquaticus gen. n. and sp. n. a non-sporulating extreme thermophile", $J$. Bacteriol. 98, 289-297, 1969.

5. E. Blöechl, R., Rachel, S. Burggraf, D. Hafenbradl, H. W. Jannasch and K. O. Stetter. "Pyrolobus fumarii, gen. and sp. nov., represents a novel group of archaea, extending the upper temperature limit for life to 113 "C", Extremophiles 1, 14-21, 1997.

6. K. Kashefi and D. Lovely. "Extending the upper temperature limit for life", Science 301, 934, 2003.

7. D. A. Cowan. "The upper temperature for life - where do we draw the line?", TRENDS Microbiology 12, 5860, 2004.

8. R. Y. Morita. "Psychrophilic bacteria", Bacteriol. Rev. 39, 144-167, 1975.

9. H. Van Heurck. "Diatomées. Éxpedition Antarctique Belge. Resultats du voyage du S. Y. Belgica en 18971898-1899 sous le commandement de Gerlache de Gomery", Rapports scientifiques Botanique 5, 1-128, 1909.

10. R. B. Hoover, E. V. Pikuta, D. Marsic, and J. Ng. "Anaerobic psychrophiles from Alaska, Antarctica, and Patagonia: Implications to possible life on Mars and Europa", in //Instruments, Methods, and Missions for Astrobiology IV, (R. B. Hoover, G. V. Levin, R. R. Paepe, and A. Yu. Rozanov, eds.) Proc. SPIE 4495, 313$324,2002$.

11. E. V. Pikuta and R. B. Hoover. "Psychrophiles and astrobiology: microbial life of frozen worlds", in I/Instruments, Methods, and Missions for Astrobiology VI (R. B. Hoover, A. Yu. Rozanov, and J. H. Lipps, eds.) Proc. SPIE, 4939, 103-116, 2003.

12. E. V. Pikuta, R. B. Hoover, D. Marsic, A. K. Bej, J. Tang, D. Cleland and P. Krader. "Psychrotolerant anaerobic bacteria from Patagonia and the permafrost tunnel of Fox, Alaska", in: $/ / 103^{\text {rd }}$ General Meeting American Society for Microbiology, May 18-22, p. 351., Washington, D.C., 2003b.

13. D. Gilichinsky, E. Rivkina, C. Bakermans, V. Shcherbakova, L. Petrovskaya, S. Ozerskaya, N. Ivanushkina, G. Kochkina, K. Laurinavichus, S. Pecheritsina, R. Fattakhova and J. M. Tiedje. "Biodiversity of cryopegs in permafrost", FEMS Microbiol. Ecology 53, 117-128, 2005.

14. J. T. Staley and J. J. Gosink. "Poles apart: biodiversity and biogeography of sea ice bacteria", Annu. Rev. Microbiol. 53, 189-215, 1999.

15. A. W. Downie, and J. Cruickshank. "The resistance of Streptococcus fecalis to acid and alkaline media", $B r$. J. Exp. Pathol. 9, 171-173, 1928.

16. C. S. Meek and C. B. Lipman. "The relation of the reaction and of salt content of the medium on nitrifying bacteria", J. Gen.Physiol. 5, 195-204, 1922.

17. K. Horikoshi and T. Akiba. "Alkalophilic microorganisms: a new microbial world", Springer-Verlag KG, Heidelberg, Germany, 1982.

18. B. J. Tindall, H. N. M. Ross and W. D. Grant. "Natronobacterium gen. nov., and Natronococcus gen. nov., two new genera of halophilic archaebacteria", Syst. Appl. Microbiol. 5, 41-57, 1984.

19. A. A. Yayanos, A. S. Dietz and R. V. Van Boxtel. "Isolation of a deep-sea barophilic bacterium and some of its growth characteristics", Science 205, 808-810, 1979.

20. H. D. Raj, F. L. Duryee, A. M. Deeney, C.H. Wang, A. W. Anderson and P. R. Elliker. "Utilization of carbohydrates and amino acids by Micrococcus radiodurans", Can. J. Microbiol. 6, 289-298, 1960.

21. J. Edmond, S. L'Haridon, E. Corre, P. Forterre and D. Prieur. "Thermococcus gammatolerans sp. nov., a hyperthermophilic archaeon from deep-sea hydrothermal vent that resists to ionizing radiation", Int. J. Syst. Evol. Microbiol 53, 847-851, 2003.

22. L. Pasteur. "Animalcules infusoires vivant sans gaz oxygène libre et déterminant des fermentations", Compt. Rend. Acad. Sci. (Paris), 52, 344-347, 1861. 
23. R. E. Hungate. "A roll tube method for cultivation of strict anaerobes", in //Methods in Microbiology (J. R. Norris, and D. W. Ribbons, eds.) 3B, 117-132. New York. Academic Press, 1969.

24. E. V. Pikuta, R. B. Hoover and J. Tang. "Microbial extremophiles at the limits of life", Critic. Rev. Microbiol. 33, 183-209, 2007b.

25. C. Knoblauch, K. Sahm and B. B. Jørgensen. "Psychrophilic sulfate-reducing bacteria isolated from permanently cold Arctic marine sediments: description of Desulfofrigus oceanense gen. nov., sp. nov., Desulfofrigus fragile sp. nov., Desulfofaba gelida gen. nov., sp. nov., Desulfotalea psychrophila gen. nov., sp. nov. and Desulfotalea arctica sp. nov. ", Int. J. Syst. Bacteriol. 49, 1631-1643, 1999.

26. R. B. Hoover and E. V. Pikuta. "Microorganisms on comets, Europa and the polar ice caps of Mars". in //Instruments, Methods, and Missions for Astrobiology VII, (R. B. Hoover, and A. Yu. Rozanov, eds.) Proc. SPIE 5163, 191-201, 2004.

27. S. S. Abyzov, N. S. Duxbury, N. E. Bobin, M. Fukuchi, R. B. Hoover, H. Kanda, I. N. Mitskevich, A. L. Mulyukin, T. Naganuma, M. N. Poglazova, and M. V. Ivanov. "Super-long anabiosis of ancient microorganisms in ice and terrestrial models for development of methods to search for life on Mars, Europa and other planetary bodies", Adv. Space Res. Cospar 38, 1191-119, 2006.

28. M. T. Zuber, D. E. Smith, S. C. Solomon, J. B. Abshire, R. S. Afzal, O. Aharonson, K. Fishbaugh, P. G. Ford, H. V. Frey, J. B. Garvin, J. W. Head, A. B. Ivanov, C. L. Johnson, D. O. Muhleman, G. A. Neumann, G. H. Pettengill, R. J. Phillips, X. Sun, H. J. Zwally, W. B. Banerdt and T. C. Duxbury. "Observations of the north polar region of Mars from the Mars Orbiter Laser Altimeter", Science 282, 2053-2060, 1998.

29. D. S. Bass and D. A. Paige. "Variability of Mars' north polar water ice cap. II. Analysis of Viking IRTM and MAWD data", Icarus 144, 397-409, 2000.

30. H. H. Kieffer, S. C. Chose, T. Z. Martin, E. D. Miner and F. D. Palluconi. "Martian North pole summer temperature: Dirty water ice", Science 194, 1341-1344, 1976.

31. R. Greve. "Waxing and Waning of the Perennial North Polar $\mathrm{H}_{2} \mathrm{O}$ Ice Cap of Mars over Obliquity Cycles", Icarus 144, 419-431, 2000.

32. M. Haberle and B. M. Jakosky. "Sublimation and transport of water from the north residual polar cap on Mars", J. Geophys. Res. 95, 1423-1437, 1990.

33. R. Paepe, R. B. Hoover and E. Van Overloop. "Patterned Ground as Evidence of Water on Mars", in// Permafrost Response on Economic Development, Environmental Security and Natural Resource Potential, NATO-ARW held in NOVOSIBIRSK, SIBERIA, 12-16 Nov. 1998 (R. Paepe, ed.) pp. 581-588. Kluewer Publishing, New York, 2001.

34. M. L. Litvak, I. G. Mitrofanov, A. S. Kozyrev, A. B. Sanin, V. I. Tretyakov, W. V. Boynton, N. J. Kelly, D. Hamara, C. Shinohara and R. S. Saunders. "Comparison between polar regions of Mars from HEND/Odyssey data", Icarus 180, 23-37, 2006.

35. I. G. Mitrofanov, M. L. Litvak, A. S. Kozyrev, A. B. Sanin, V. I. Tret'yakov, V. Yu. Grin'kov, W. V. Boynton, C. Shinohara, D. Hamara and R. S. Saunders. "Soil Water Content on Mars as Estimated from Neutron Measurements by the HEND Instrument On board the 2001 Mars Odyssey Spacecraft", Solar System Research 38, 253-357, 2004.

36. L.O. Odokuma and A. A. Dickson. "Bioremediation of a Crude Oil Polluted Tropical Rain Forest Soil", Global J. Environmental Sciences 2, 29-40, 2003.

37. E. V. Pikuta and R. B. Hoover. "Growth of the facultative anaerobes from Antarctica, Alaska, and Patagonia at low temperatures", in: //Instruments Methods and Missions for Astrobiology VIII, Proc.SPIE 5555, 160$191,2004 b$.

38. R. B. Hoover and D. Gilichinsky. "Significance to Astrobiology of Microorganisms in Permafrost and Ice". in //Permafrost Response on Economic Development, Environmental Security and Natural Resource Potential, (R. Paepe, Ed) pp. 553-580. NATO-ARW held in NOVOSIBIRSK, SIBERIA, 12-16 Nov. 1998. Kluewer Publishing, New York, 2001.

39. R. L. Mancinelli, T. F. Fahlen, R. Landheim and M. R. Klovstad. "Brines and evaporites: analogs for Martian life", Adv. Space Res. 33, 1244-1246, 2004.

40. S. S. Abyzov, R. B. Hoover, S. Imura, I. N. Mitskevich, T. Naganuma, M. N. Poglazova and M. V. Ivanov. "Comparative Results of Using Different Methods for Discovery of Microorganisms in Very Ancient Layers of the Central Antarctic Glacier above Lake Vostok", Adv. .Space Res. Cospar. 33, 1222-1230, 2004.

41. E. V. Pikuta, R. B. Hoover, D. Marsic, A. K. Bej, J. Tang and P. Krader. "Carnobacterizim pleistocaenium sp. nov., a novel psychrotolerant, facultative anaerobe isolated from Fox Tunnel permafrost, Alaska", Int. J. Syst. Evol. Microbiol 55, 473-478, 2005a. 
42. E. V. Pikuta, R. B. Hoover, A K. Bej, D. Marsic, W. B. Whitman, P. E. Krader and J. Tang. "Trichococcus patagoniensis sp. nov., a facultative anaerobe that grows at $-5^{\circ} \mathrm{C}$, isolated from penguin guano in Chilean Patagonia", Int. J. Syst. Evol. Microbiol. 56, 2055-2062, 2006 a.

43. M. J. Harris, N. C. Wickramasinghe, D. Lloyd, J. V. Narlikar, P. Rajaratnam, M. P. Turner, S. Al-Mufti, M. K. Wallis, S. Ramadurai and F. Hoyle. "The detection of living cells in stratospheric samples", in //Instruments, Methods, and Missions for Astrobiology IV (R. B. Hoover, A. Rosanov, and R. Paepe, Eds.) Proc.SPIE, San Diego, 4495, 192-198, 2002.

44. E. V. Pikuta and R. B. Hoover. "Astrobiological significance of chemolithoautotrophic acidophiles", in Instruments, methods, and missions for astrobiology VII, eds. RB Hoover, AYu Rozanov. Proceedings of SPIE 5163, 179-1490, 2004a.

45. D. S. McKay, E. K. Gibson, K. L. Thomas-Keprta, H. Vali, C. S. Romanek, S. J. Clemett, X. D. F. Chillier, C. R. Maechling and R. N. Zare. "Search for past life on Mars: Possible relic biogenic activity in Martian meteorite ALH84001", Science 273, 924-930, 1996.

46. M. Wadhwa and G. W. Lugmair. "The formation age of carbonates in ALH 84001", Meteoritics 31, A145, 1996.

47. E. V. Pikuta, E. N. Detkova, A. K. Bej, D. Marsic and R. B. Hoover. "Anaerobic halo-alkaliphilic bacterial community of athalassic, hypersaline Mono Lake and Owens Lake in California", in //Instruments, Methods, and Missions for Astrobiology V (R. B. Hoover, A. Yu. Rozanov, and R. R Paepe, eds.) Proceedings of SPIE 4859, 130-144, 2003a.

48. R. B. Hoover. "Microfossils, biominerals, and chemical biomarkers in meteorites", in //Perspectives in Astrobiology, NATO Science Series: Life and Behavioural Sciences (R. B. Hoover, R. R. Paepe, and A. Yu. Rozanov, eds.) IOS Press, Amsterdam, Netherlands, 336, 43-65, 2005.

49. R. B. Hoover. "Fossils of prokaryotic microorganisms in the Orgueil meteorite", in //Instruments, Methods and Missions for Astrobiology IX (R. B. Hoover, A. Yu. Rozanov, and G. V. Levin, eds.) SPIE, 630902, 1-17, 2006.

50. F. Hoyle and C. Wickramasinghe. "Comets - A Vehicle for Panspermia", in //Comets and the Origin of Life, (C. Ponnamperuma ed.), pp. 222-239. D. Reidel Publ. Co., Dordrecht, 1981.

51. R. B. Hoover, F. Hoyle, N. C. Wickramasinghe, M. J. Hoover and S. Al-Mufti. "Diatoms on Earth, Comets, Europa, and in Interstellar Space", Earth, Moon, and Planets 35, 19-45, 1986.

52. E. V. Pikuta, R. B. Hoover, A. K. Bej, D. Marsic, E. N. Detkova, W. B. Whitman and P. Krader. "Tindallia californiensis sp. nov., a new anaerobic, haloalkaliphilic, spore-forming acetogen isolated from Mono Lake in California", Extremophiles 7, 327-334, 2003d.

53. E. V. Pikuta, T. Itoh, P. Krader, J. Tang, W. B. Whitman and R. B. Hoover. "Anaerovirgula multivorans gen. nov., sp. nov., a novel spore-forming, alkaliphilic anaerobe isolated from Owens Lake, California", Int. $J$. Syst. Evol. Microbiol. 53, 2623-2629, 2006 b.

54. E. V. Pikuta, D. Marsic, T. Itoh, A. K. Bej, J. Tang, W. B. Whitman, J. Ng, O. K. Garriott and R. B. Hoover. "Thermococcus thioreducens sp. nov., a novel hyperthermophilic, obligately sulfur-reducing archaeon from a deep-sea hydrothermal vent", Int. J. Syst. Evol. Microbiol. 57, 1612-1618, 2007. 